\title{
Design, Synthesis And Invitro Biological Evaluation of Benzothiazole, Indole And Imidazole Derivatives As Anti Tubercular Agents Targeting Glutamine Synthetase-1
}

\section{Ayyadurai Jerad Suresh \\ Madras Medical College \\ Venkatesan Meenakumari \\ Madras Medical College \\ Ponmozhi kalairasi \\ Madras Medical College}

\section{Thangamariyappan Kanimozhi \\ Madras Medical College}

Surya Parakkot Ramakrishnan ( $\sim$ suryapr2005@gmail.com )

Madras Medical College https://orcid.org/0000-0001-7978-2751

\section{Research article}

Keywords: Tuberculosis, MABA, Benzothiazole, Imidazole, Indole, Glutamine synthetase, Autodock, Docking

Posted Date: August 26th, 2020

DOI: https://doi.org/10.21203/rs.3.rs-52122/v1

License: (c) (i) This work is licensed under a Creative Commons Attribution 4.0 International License. Read Full License 


\section{Abstract}

Due to the emergence of multidrug-resistant TB (MDR-TB) and extensively drug resistant (XDR) TB, the disease becomes a major health security threat globally ${ }^{2}$. In order to eliminate DRTB there is an urgent need of novel molecules which are very effective with lesser side effects. Hence this research work focused to work on synthesis and biological evaluation of benzothiazole, indole and imidazole derivatives as anti tubercular agents. Benzothiazole, indole and imidazole moieties were designed and docked against glutamine synthetase (PDB ID$3 Z X R)$ using Autodock ${ }^{\circledR}$ tools software. Compounds with minimum binding energy were selected and screened for in silico toxicity prediction using osiris ${ }^{\circledR}$ software and in silico drug likeness prediction by using molinspiration ${ }^{\circledR}$ software. The compounds were synthesized and characterized by IR, ${ }^{1} \mathrm{H}$ NMR and LC-MS. Anti-tubercular activity was evaluated by Microplate Alamar Blue Assay (MABA) method. Among the synthesized compounds, indole derivatives and imidazole derivatives was found to be active at micro gram level.

\section{Introduction}

Tuberculosis is an infectious disease that usually attacks the lungs and also spread to other parts of the body, like brain and spine. Today TB has become a major health threat due to the emergence of Multi-drug resistance tuberculosis (MDR-TB), Extensively drug resistance tuberculosis(XDR-TB) and Totally Drug Resistant (TDR) tuberculosis[1, 2].

Benzothiazole is a privileged bicyclic ring system consists of phenyl ring fused with thiazole ring. Derivatives of benzothiazole possess important pharmacological activities like anti-diabetice, anticonvulsant, analgesic and antiinflammatory activities [3]. Indole nucleus continuously drawing interest for development of newer drug moiety due to its wide range of pharmacological activities. Indole derivatives were reported to have antioxidant, antibacterial and antitubercular activities [4, 5]. A new series of $1 \mathrm{H}$-indole-2, 3-dione derivatives were reported for in vitro antitubercular activity against Mycobacterium tuberculosis H37Rv [10]. As per literature surveys, Imidazole derivatives are also well known for its pharmacological activities including antimycobacterial, antitubercular [6, 7]. Hence we decided to design and synthesis benzothiazole, Indole and Imidazole derivatives as anti tubercular agents against target enzyme.

There are various biosynthetic enzymes that are essential for the survival of the Mycobacterium and are considered as potential drug targets. As per reported, a comprehensive in silico target identification pipeline for Mycobacterium tuberculosis, there are a total of 451 high-confidence targets [8]. Glutamine synthetase-1 is one of the key enzymes, which is critical for the survival and growth of MTB [9]. Glutamine synthetase, takes part in nitrogen metabolism, catalyses the formation of glutamine from glutamate and ammonia in the presence of adenosine triphosphate (ATP). MtGS plays an important role in cell wall biosynthesis, specifically via the production of a poly-L-glutamateglutamine component found exclusively in pathogenic mycobacteria. Hence forth, the inhibition of Glutamine Synthetase secreted by $M$. tuberculosis is sufficient to inhibit the growth of the bacterium, suggesting that MtGS might be a valid target for anti-tubercular agents [10]. Thus Glutamine synthetase selected as target of interest. The enzyme was downloaded from the Protein Data Bank (ID 3ZXR) in the pdb format and used for in silico molecular docking study.

\section{Results And Discussion}


Table 1: Physical properties of synthesized compounds.

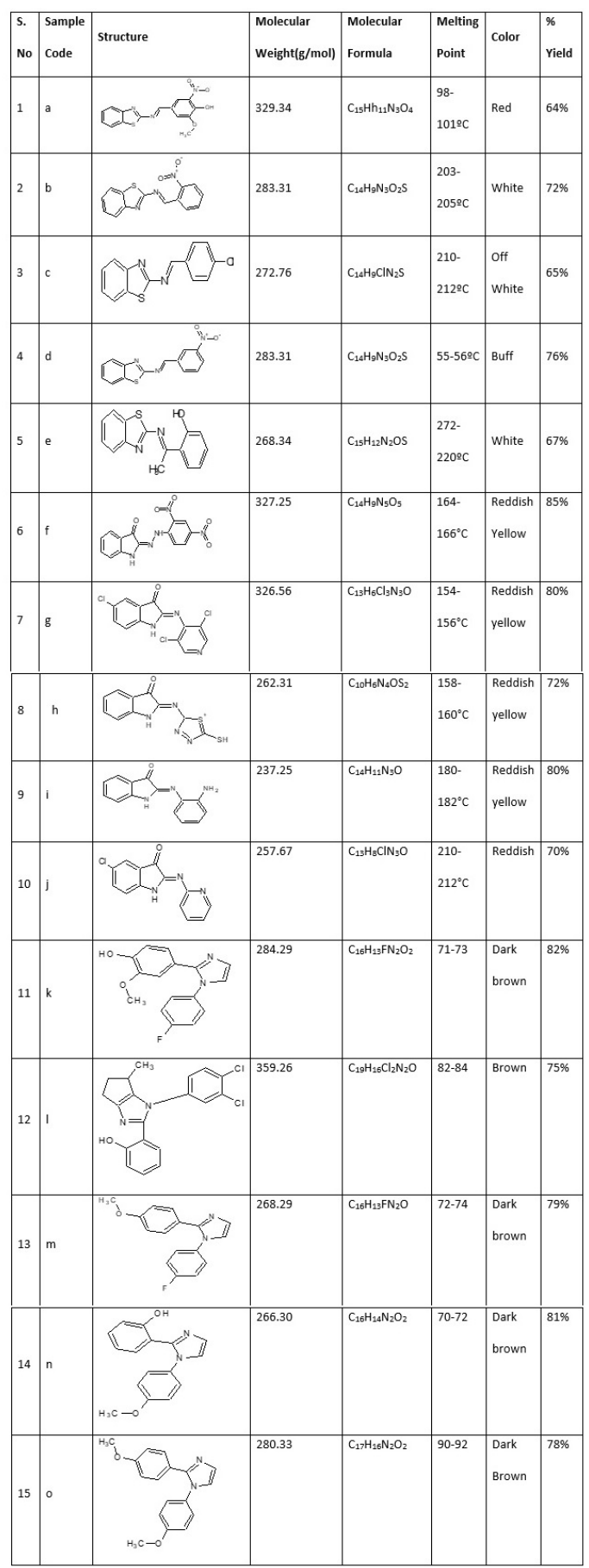

\section{Molecules docking view with target enzyme glutamine Synthetase (PDB ID-3ZXR)}

\section{Spectral studies}

a: 4-[(E)-(1,3-benzothiazol-2-ylimino)methyl]-2-methoxy-6-nitrophenol. IR: $1554.35 \mathrm{~cm}^{-1}\left(\mathrm{NO}_{2} \mathrm{str}^{2}, 1620.09 \mathrm{~cm}^{-1}(\mathrm{C}=\mathrm{Nstr})\right.$, $2815.86 \mathrm{~cm}^{-1}(\mathrm{C}=0 \mathrm{str}), 2877.50 \mathrm{~cm}^{-1}$ (Al-CHstr). NMR: $\delta$ (2.6 ppm, multiplet, 2H), (3.6 ppm, multiplet, 3H), (6.9 ppm, multiplet, 6H). MASS: $325.05 \mathrm{~m} / \mathrm{z}$.

b: $N-\left[(E)-\left(2-\right.\right.$ nitrophenyl)methylidene]-1,3-benzothiazol-2-amine. IR: $1532.16 \mathrm{~cm}^{-1}(\mathrm{~N}=0 \mathrm{str}), 1604.66 \mathrm{~cm}^{-1}(\mathrm{C}=\mathrm{Nstr})$, 1536.75 $\mathrm{cm}^{-1}$ (Ar C=Cstr),2877.50 $\mathrm{cm}^{-1}$ (Al-CHstr). NMR: (7.6 ppm, multiplet, 4H), (6.9-7.3 ppm, multiplet, 5H). MASS: 


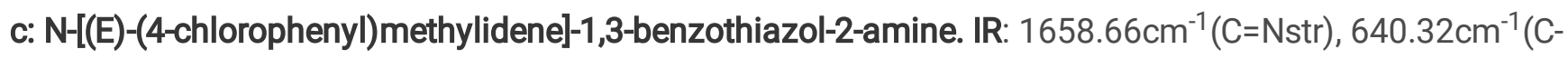
Clstr),2900.73 $\mathrm{cm}^{-1}$ (Al-CHstr). NMR: $\delta$ (2.6 ppm, multiplet, $\left.1 \mathrm{H}\right),(7.5 \mathrm{ppm}$, multiplet, $8 \mathrm{H})$. MASS: $274.95 \mathrm{~m} / \mathrm{z}$.

d: $N-(E)-\left(3-\right.$-nitrophenyl)methylidene]-1,3-benzothiazol-2-amine. IR: $1535.22 \mathrm{~cm}^{-1}(\mathrm{~N}=0 \mathrm{str}), 2360.70 \mathrm{~cm}^{-1}(\mathrm{C}=\mathrm{Nstr})$, $2877.50 \mathrm{~cm}^{-1}$ (Al-CHstr). NMR: (7.8 ppm, multiplet, $\left.5 \mathrm{H}\right),(10.1 \mathrm{ppm}$, multiplet, $4 \mathrm{H})$. MASS: $283.9 \mathrm{~m} / \mathrm{z}$.

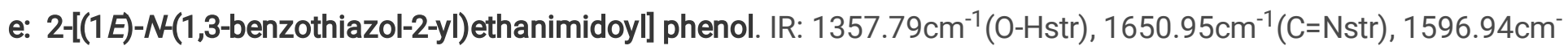
${ }^{1}$ (Ar C=Cstr),2885.30 $\mathrm{cm}^{-1}$ (Al-CHstr). NMR: $\delta(2.51 \mathrm{ppm}$, Singlet, 3H), $(8.1 \mathrm{ppm}$, multiplet, $1 \mathrm{H}),(6.9-7.3 \mathrm{ppm}$, multiplet, 8H). MASS: $267.9 \mathrm{~m} / \mathrm{z}$.

f: (2Z)-2-[2-(2,4-dinitrophenyl)hydrazinylidene]-1,2-dihydro-3Hindol-3-one:IR:2885( $\left.\mathrm{cm}^{-1}\right)$ C-H Stretching, $1496.65\left(\mathrm{~cm}^{-}\right.$

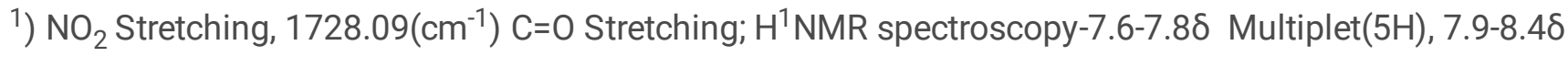
Multiplet(4H).

g: (2Z)-5-chloro-2-[(3,5-dichloropyridin-4-yl)imino]-1,2-dihydro-3Hindol-3-one: IR -2854.44( $\left.\mathrm{cm}^{-1}\right)$ C-H stretching, 794.61 $\left(\mathrm{cm}^{-1}\right) \mathrm{C}-\mathrm{Cl}$ stretching, $1728.09\left(\mathrm{~cm}^{-1}\right) \mathrm{C}=0$ Stretching; $H^{1} \mathrm{NMR}$ spectroscopy-6.8-7.5 $\delta$ multiplet $(2 \mathrm{H}), 3.3-4.2 \delta$ Triplet(2H)

h): (2Z)-2-[(5-sulfanyl-1,3,4-thiadiazol-2-yl)imino]-1,2-dihydro-3Hindol-3-one: IR - 2908.44( $\left.\mathrm{cm}^{-1}\right)$ C-H stretching, 1612.37 (cm $\left.{ }^{-1}\right) \quad C=N$ stretching, 748.33 $\left(\mathrm{cm}^{-1}\right) \quad$ C-S stretching; $H^{1}$ NMR spectroscopy- 6.9-7.5 $\delta$ Doublet(5H),7.6-8.1 $\delta$ Multiplet(1H)

i: (2Z)-2-[(2-aminophenyl)imino]-1,2-dihydro-3Hindol-3-one: IR- 3062.73( $\left.\mathrm{cm}^{-1}\right) \quad$ C-H stretching, $1612.37\left(\mathrm{~cm}^{-1}\right) \mathrm{C}=\mathrm{N}$ stretching, $1720.38\left(\mathrm{~cm}^{-1}\right) \quad$ C=0 Stretching; $\mathrm{H}^{1} \mathrm{NMR}$ spectroscopy-6.8-8.3 $\delta \operatorname{Triplet}(9 \mathrm{H}), 2.5-3.3 \delta \operatorname{Multiplet}(2 \mathrm{H})$

j: (2Z)-5-chloro-2-(pyridin-2-ylimino)-1,2-dihydro-3H-indol-3-one: IR -2877.58 $\left(\mathrm{cm}^{-1}\right)$ C-H stretching1612.37( $\left.\mathrm{cm}^{-1}\right) \mathrm{C}=\mathrm{N}$ stretching, $748.39 \mathrm{C}-\mathrm{Cl}\left(\mathrm{cm}^{-1}\right)$ stretching, $\mathrm{H}^{1} \mathrm{NMR}$ spectroscopy- 6.8-7.8 $\delta \operatorname{Triplet}(6 \mathrm{H})$, $3.7 \delta \operatorname{Multiplet}(2 \mathrm{H})$

k: 4-[1-(4-fluorophenyl)-1 H-imidazol-2-yl]-2-methoxyphenol: IR : 1226.64 ArOHStr, 1350.07 -C-F Str, 1504.37 -C=N Str, 1118.63 -C-O- Str. NMR $\delta 3.8 \mathrm{ppm}$ Multiplet 2H , 6.6ppm Multiplet 4H, 7.2ppm Multiplet 7H MASS m/z : 284.90 $\mathrm{g} / \mathrm{mol}$.

I: 2-[1-(3,4-dichlorophenyl)-6-methyl -1,4,5,6-tetrahydrocyclopenta[d]imidazol-2-yl] phenol: IR : 671.18 C-CIStr, 1234.35 ArOHStr, 1396.30 -C=N Str, 3062.73 Ar-H Str, 1697.23 C=C Str. NMR ס 2.5ppm Multiplet 3H, 6.7ppm Multiplet 5H, $7.4 \mathrm{ppm}$ Multiplet $8 \mathrm{H}$. MASS $\mathrm{m} / \mathrm{z}: 356.95 \mathrm{~g} / \mathrm{mol}$.

m: 1-(4-fluorophenyl)-2-(4-methoxyphenyl)-1H-imidazole: IR : 1157.20 C-F Str, 1512.06 C=N Str, 1249.78 C-O Str, 3006.73 Ar-H Str. NMR 83.7ppm Multiplet 3H, 6.4ppm Multiplet 8H, 7.8ppm Multiplet 2H. MASS m/z:269.02 g/mol.

n: 2-[1-(4-methoxyphenyl)-1H-imidazol-2-yl]phenol: IR : 1357.79 ArOHStr, 1496.65 C=N Str, 1242.07 C-0 Str, 3055.02 Ar-H Str. NMR 83.8ppm Multiplet 3H, 6.9ppm Multiplet 5H, 7.1ppm Multiplet 6H. MASS m/z :267.11 g/mol.

o: 1,2-bis(4-methoxyphenyl)-1H-imidazole: IR : 1512.08 C=N Str, 1026.05 C-0 Str, 3008.73 Ar-H Str. NMRס 3.3ppm Multiplet 6H,6.6ppm Multiplet 8H, 7.4ppm Multiplet 2H. MASS m/z: $280.95 \mathrm{~g} / \mathrm{mol}$. 
Biological Evaluation

Table 2: anti tubercular activity for the synthesized compounds

\begin{tabular}{|c|c|c|c|c|c|c|c|c|c|}
\hline S.N & JE & & & & & & & . & 50.8 \\
\hline 1 & $\mathbf{A}$ & $\mathbf{S}$ & $\mathbf{S}$ & $\mathbf{R}$ & $\mathbf{R}$ & $\mathbf{R}$ & $\mathbf{R}$ & $\mathbf{R}$ & $\mathbf{R}$ \\
\hline 2 & b & $\mathbf{S}$ & $\mathbf{R}$ & $\mathbf{R}$ & $\mathbf{R}$ & $\mathbf{R}$ & $\mathbf{R}$ & $\mathbf{R}$ & $\mathrm{R}$ \\
\hline 3 & C & $\mathbf{S}$ & $\mathbf{R}$ & $\mathbf{R}$ & $\mathbf{R}$ & $\mathbf{R}$ & $\mathbf{R}$ & $\mathbf{R}$ & $\mathbf{R}$ \\
\hline 4 & $\mathrm{~d}$ & $\mathbf{S}$ & S & $\mathrm{S}$ & S & S & $\mathbf{R}$ & $\mathbf{R}$ & $\mathrm{R}$ \\
\hline 5 & e & $\mathbf{S}$ & $\mathbf{S}$ & S & $\mathbf{S}$ & $\mathbf{R}$ & $\mathbf{R}$ & $\mathbf{R}$ & $\mathbf{R}$ \\
\hline 6 & f & $\mathbf{S}$ & $\mathbf{S}$ & $\mathbf{R}$ & $\mathbf{R}$ & $\mathbf{R}$ & $\mathbf{R}$ & $\mathbf{R}$ & $\mathrm{R}$ \\
\hline 7 & $\mathrm{~g}$ & $\mathbf{S}$ & $\mathbf{S}$ & $\mathrm{S}$ & $\mathbf{S}$ & S & S & $\mathbf{S}$ & $\mathrm{R}$ \\
\hline 8 & $\mathbf{h}$ & S & S & $\mathbf{R}$ & $\mathbf{R}$ & $\mathbf{R}$ & $\mathbf{R}$ & $\mathbf{R}$ & $\mathrm{R}$ \\
\hline 9 & $\mathbf{i}$ & $\mathbf{S}$ & S & S & $\mathbf{S}$ & S & S & $\mathbf{S}$ & $\mathbf{R}$ \\
\hline 10 & $\mathbf{j}$ & $\mathbf{S}$ & $\mathbf{S}$ & $\mathbf{R}$ & $\mathbf{R}$ & $\mathbf{R}$ & $\mathbf{R}$ & $\mathbf{R}$ & $\mathrm{R}$ \\
\hline 11 & $\mathbf{k}$ & $\mathbf{S}$ & $\mathbf{S}$ & $\mathrm{S}$ & $\mathbf{R}$ & $\mathbf{R}$ & $\mathbf{R}$ & $\mathbf{R}$ & $\mathbf{R}$ \\
\hline 12 & 1 & $\mathbf{S}$ & $\mathbf{S}$ & $\mathbf{R}$ & $\mathbf{R}$ & $\mathbf{R}$ & $\mathbf{R}$ & $\mathbf{R}$ & $\mathrm{R}$ \\
\hline 13 & $\mathrm{~m}$ & $\mathbf{S}$ & S & $\mathrm{S}$ & $\mathbf{R}$ & $\mathbf{R}$ & $\mathbf{R}$ & $\mathbf{R}$ & $\mathrm{R}$ \\
\hline 14 & $\mathbf{n}$ & S & S & $\mathrm{S}$ & $\mathbf{R}$ & $\mathbf{R}$ & $\mathbf{R}$ & $\mathbf{R}$ & $\mathbf{R}$ \\
\hline 15 & 0 & S & $\mathbf{S}$ & $\mathbf{S}$ & $\mathbf{S}$ & S & $S$ & $\mathbf{R}$ & $\mathrm{R}$ \\
\hline
\end{tabular}

NOTE: S - Sensitive $\quad \mathbf{R}$ - Resistant

Standard Strain used:Mycobacteria tuberculosis (Vaccine strain, H37Rv strain)

ATCC No- 27294.

Standard values for the Anti-Tb test which was performed.

- Pyrazinamide- $3.125 \mu \mathrm{g} / \mathrm{ml}$

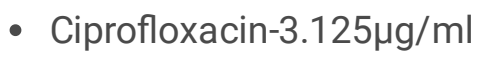

- Streptomycin- $6.25 \mu \mathrm{g} / \mathrm{ml}$

Table 3: A Comparative docking Study of Synthesized Compounds with standard anti tubercular drugs 


\begin{tabular}{|c|c|c|c|}
\hline SI NO & COMPOUND NAME & DOCKING SCORE in Kcal/mol & MABA ASSAY (MIC) $\mu \mathrm{g} / \mathrm{ml}$ \\
\hline 1 & a & -7.73 & 50 \\
\hline 2 & b & -9.47 & 100 \\
\hline 3 & c & -8.84 & 100 \\
\hline 4 & $\mathrm{~d}$ & -7.69 & 6.25 \\
\hline 5 & e & -6.56 & 12.5 \\
\hline 6 & $\mathrm{f}$ & -7.56 & 50 \\
\hline 7 & $g$ & -7.1 & 1.6 \\
\hline 8 & $\mathrm{~h}$ & -6.57 & 50 \\
\hline 9 & i & -5.83 & 1.6 \\
\hline 10 & $j$ & -6.39 & 50 \\
\hline 11 & $\mathbf{k}$ & -5.54 & 25 \\
\hline 12 & 1 & -7.78 & 50 \\
\hline 13 & $\mathrm{~m}$ & -5.44 & 25 \\
\hline 14 & $\mathrm{n}$ & -5.91 & 25 \\
\hline 15 & 0 & -6.02 & 3.125 \\
\hline \multirow{2}{*}{$\begin{array}{l}\text { STD } \\
\text { DRUGS }\end{array}$} & PYRAZINAMIDE (Z) & -4.69 & 3.125 \\
\hline & CIPROFLOXACIN & -6.45 & 3.125 \\
\hline
\end{tabular}

\section{Experimental}

Molecular Docking Studies: Drug discovery is the process by which new agents are designed or discovered. Computer Aided Drug Design uses Computational tools and software, helps in the identification of new compounds. The designed molecules were docked against the target protein Glutamine synthetase- 1 using AutoDock ${ }^{\circledR}$ tools 1.5 .6 software. It is an automated procedure for predicting the interaction of ligands with biomacromolecular targets. The current version of AutoDock ${ }^{\circledR}$ tool using the Lamarckian Genetic Algorithm and empirical free energy scoring function, typically will provide reproducible docking results for ligands with approximately 10 flexible bonds. The quality of any docking results depends on the starting structure of both the protein and the potential ligand [11, 12].

\section{Synthetic Experiments}

Scheme1: General reaction of Synthesis of Benzothiazole Schiff's bases (a-e) (see Supplementary Files)

Procedure: Equimolar quantities of Aldehyde $(0.01 \mathrm{~mol})$ and amine $(0.01 \mathrm{~mol})$ were added into $20 \mathrm{~mL}$ of absolute ethanol and few $\mathrm{mL}$ of glacial acetic acid was added to it. Reaction mixture is refluxed for $8-12 \mathrm{hrs}$ at $60^{\circ} \mathrm{C}$. The Completion of reaction was confirmed by TLC. This mixture was poured into crushed ice. The precipitate obtained was filtered, dried and re crystallized using ethanol. 
Reactants used:

Amine used: 2-Amino benzothiazole. Aldehydes used: 5-nitro Vanillin, P-Chloro benzaldehyde, 2-nitro Benzaldehyde, 3-nitro Benzaldehyde, 2-hydroxy Acetophenone

Scheme 2: Synthesis of Schiff bases of isatin derivatives: (f-j) (see Supplementary Files)

Procedure: Equimolar quantities of ketone $(0.01 \mathrm{~mol})$ and Para-substituted amine $(0.01 \mathrm{~mol})$ are added into $20 \mathrm{~mL}$ of absolute ethanol and $5 \mathrm{~mL}$ of glacial acetic acid is added to it. Reaction mixture is refluxed for $24 \mathrm{hrs}$ at $60^{\circ} \mathrm{C}$. Completion of reaction is confirmed by TLC. The product obtained was filtered and dried. Recrystallisation is done by using ethanol.

Ketones used: Isatin; 5-chloro Isatin

Primary amines used: 2, 4 -dinitro phenyl hydrazine; 4-amino 3,5-dichloro pyridine; 5-amino 1,3,4-thiadiazole-2-thiol; o-phenylene diamine; 2-amino pyridine

Scheme 3: Imidazole derivatives (k-0) (see Supplementary Files)

Procedure: A Mixture of $0.1 \mathrm{~mol}$ of Diketone, $0.1 \mathrm{~mol}$ of substituted aromatic aldehyde and $0.1 \mathrm{~mol}$ of primary amine, $0.1 \mathrm{~mol}$ of Ammonium acetate and acetic acid was taken in a Round bottom flask. Subjected to reflux (8-12 hours). On completion of reaction as monitored by TLC at an interval of 30 minutes. This mixture was poured into crushed ice. The obtained precipitated was filtered, dried and recrystallized using ethanol.

Diketone used: Glyoxal, 3-Methylcyclopentane-1,2-dione

Aldehyde used: Vanillin, Salicylaldehyde, Anisaldehyde

Primary amine used: 3,4 -Dichloroaniline, 4-Fluoroaniline, Anisidine

\section{Characterization}

Justification of purification was done by the melting point and Thin layer chromatography. The Melting point of the synthesized compounds was determined in open capillary tube and values are reported uncorrected. Thin layer chromatography was done to assess the course of reaction and the purity of the intermediates and the final compounds. Visualization of the compounds on chromatographic plates was done by exposure to iodine vapors. The IR absorption spectra were recorded by ABB MB 3000-PH FT-IR Spectrometer using KBr disk. ${ }^{1} \mathrm{H}-\mathrm{NMR}$ spectra were recorded on Bruker Advance $500(300 \mathrm{MHz})$ Spectrometer in CDCl3/DMSO-d6 as a solvent, the chemical shifts $\delta$ are expressed in ppm using TMS as internal standard. Mass spectra were measured using a high-resolution GCMS.

\section{Biological Evaluation}

The designed and synthesized molecules need to be screened for their activity to inhibit the growth of the Mycobacterium tuberculosisusing microplateAlamar Blue assay (MABA).Alamar blue dye is used as an indicator for the determination of viable cells. The oxidized form, Resazurin is non- toxic, non-fluorescent and blue in colour which becomes pink and fluorescent upon reduction to resorufin by viable cells [13, 14].

\section{Conclusion}


The research work concludes that the synthesized anti-tubercular compounds might effectively inhibit the chosen target Glutamine Synthetase 1 which is essential for the Mycobacterial Tuberculosis.

To conclude, a series of benzothiazole Schiff bases were designed, docked, synthesized and evaluated against Glutamine synthetase-1 enzyme which is critical for the survival and growth of MTB. The results shown Minimum Inhibitory Concentration in the range between $100-6.25 \mu \mathrm{g} / \mathrm{ml}$. Compound " $\mathrm{d}$ " was found to be as sensitive as streptomycin $(6.25 \mu \mathrm{g} / \mathrm{ml})$ and other compounds found to have less activity when compared to the standard drugs.

A series of Schiff bases of isatin derivatives as Schiff bases were designed, docked, synthesized and evaluated for anti tb activity. The Minimum Inhibitory Concentration of the synthesized compounds ranges from 50-1.6 $\mu \mathrm{g} / \mathrm{ml}$. The compounds " $\mathrm{g}$ " and " $\mathrm{i}$ " showed activity at $1.6 \mu \mathrm{g} / \mathrm{ml}$ concentrations which is compared to the activity of the standard drugs. A series of imidazole derivatives synthesized and tested against mtb activity. The Minimum

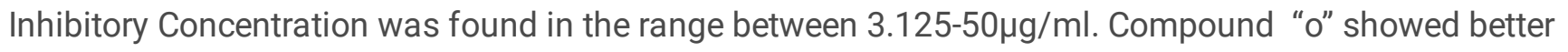
antitubercular activity at $3.125 \mu \mathrm{g} / \mathrm{ml}$ concentrations which are comparable to the activity of the standard drug pyrazinamide. The standard drugs Pyrazinamide, Ciprofloxacin and Streptomycin shows anti-mycobacterial activity at $3.125 \mu \mathrm{g} / \mathrm{ml}, 3.125 \mu \mathrm{g} / \mathrm{ml}$ and $6.25 \mu \mathrm{g} / \mathrm{ml}$ concentration respectively. Further in vivo and clinical studies required to confirm the activity of the synthesized compounds.

\section{Declarations}

\section{ACKNOWLEDGEMENTS}

All individuals listed as authors have substantially contributed in this manuscript. Ayyadurai Jerad Suresh, is the mentor of this project work, analyzed the reporting of the work. Parakkot Ramakrishnan Surya is equally involved in the article's analysis, reporting, framing as well as drafting the manuscript. Venkatesan Meenakumari, Ponmozhi kalairasi and Thangamariyappan Kanimozhi performed the design and synthetic work as a part of their MPharm research work.

\section{FUNDING}

There was no funding received for this project work

\section{COMPLIANCE WITH ETHICAL STANDARDS}

Hereby declaring that, this manuscript doesn't have an individuals' data, such as personal detail, audio-video material etc. Also states that, it doesn't involve human studies. In this research work there is no animals involved.

\section{CONFLICT OF INTEREST}

The authors have no conflict of interest.

\section{CONSENT TO PUBLISH}

Hereby all the authors are declaring that, we are approved and given consent to publish the manuscript in Russian Journal of Bioorganic Chemistry.

\section{AUTHORS CONTRIBUTION}


All authors are contributed equally in the manuscript preparation.

\section{AUTHORS INFORMATION}

Ayyadurai Jerad Suresh ${ }^{1}$ - MPharm.; Ph.D.; MBA. Principal, College of Pharmacy, Madras Medical College, Affiliated to "The Tamil Nadu Dr. M.G.R Medical University", Chennai-03, Tamil Nadu, India.

Venkatesan Meenakumari ${ }^{1}$ - MPharm; College of Pharmacy, Madras Medical College, Affiliated to "The Tamil Nadu Dr. M.G.R Medical University", Chennai-03, Tamil Nadu, India.

Ponmozhi kalairasi ${ }^{1}$ - MPharm; College of Pharmacy, Madras Medical College, Affiliated to "The Tamil Nadu Dr. M.G.R Medical University", Chennai-03, Tamil Nadu, India.

Thangamariyappan Kanimozhi1- MPharm Scholar, College of Pharmacy, Madras Medical College, Affiliated to "The Tamil Nadu Dr. M.G.R Medical University", Chennai-03, Tamil Nadu, India.

Parakkot Ramakrishnan Surya2* ${ }^{*}$ MPharm.; Ph.D.; MBA. (Former Research Scholar, College of Pharmacy, Madras Medical College, Affiliated to “The Tamil Nadu Dr. M.G.R Medical University”, Chennai-03, Tamil Nadu, India) Currently working as Assistant Professor, School of pharmacy, Sathyabama Institute of Science and Technology, Rajiv Gandhi Salai, Chennai- 600119, Tamil Nadu, India.

\section{References}

1. https://afro.who.int/health-topics/tuberculosis-tb

2. Global Tuberculosis Report (2018) ISBN 978-92-4-156564-6 @ World Health Organization 2018

3. Shiwani J, Abhinav PM, Ashish S (2012) The Different Kinds of Reaction involved in synthesis of 2-substituted Benzothiazole and its derivatives: A Review. Research Journal of Pharmaceutical Biological Chemical Sciences $3(1): 631$

4. Hardik P, Nilesh D, Jagath P, Bhagirath $P$ (2012) Recent advance in anticancer activity of indole derivatives. International journal of drug research technology 2(3):225-230

5. Amit KS, Raj KP, Chan SS (2013) Synthesis, characterization and pharmacological evaluation of some novel 3indole derivatives. Der pharma chemica 5(2):311-319

6. Mats L, Lagerlund L, Odell R, Daniel M, Anneli N (2009) Functionalized 3-amino-imidazo[1,2-a]pyridines: A novel class of drug-like Mycobacterium tuberculosis glutamine synthetase inhibitors. Bioorg Med Chem Lett 19(16):4790-4793

7. Purnima M, Wakode SR, Avneet K, Keshav A, Hitesh K (2016) A review- Imidazole synthesis and its biological activities. International Journal of Pharmaceutical Science Research 1(7):12-16

8. Theodora K, Georgios A, Spyroulias GP, Patrinos A, Minos-Timotheos M (2016) Computational approaches in target identification and drug discovery. Computational Structural Biotechnology Journal 14:177-184

9. Einsberg D, Almassy RJ, Janson CA, Chapman MS, Suh SW, Cascio D, Smith WW. Some evolutionary relationships of the primary biological catalysts glutamine synthetase and Rubisco, Cold sparing Harb. Symp. Quant. Boil. 1987; 52: 483 - 90

10. Berlicki L, Kafarski (2008) Inhibitors of glutamine synthetase and their potential application in medicine. Mini Rev Med Chem 8(9):869-878 
11. Laurie AT et al (2005) Q-site finder, energy based method for the prediction of protein-ligand binding sites. Bioinformatics 21(9):1908-1916

12. Morris GM, Huey R, Lindstrom W et al (2009) AutoDock ${ }^{4}$ and AutoDockTools ${ }^{4}$ : automated docking with selective receptor flexibility. J Comput Chem 30(16):2785-2791

13. Nakayama GR, Caton MC, Nova MP, Parandoosh Z (1997) Assessment of the Alamar Blue assay for cellular growth and viability in vitro. J Immunol Methods 204(2):205-208

14. Rampersad SN (2012) Multiple applications of Alamar Blue as an indicator of metabolic function and cellular health in cell viability bioassays. Sensors 12(12):12347-12360

\section{Figures}

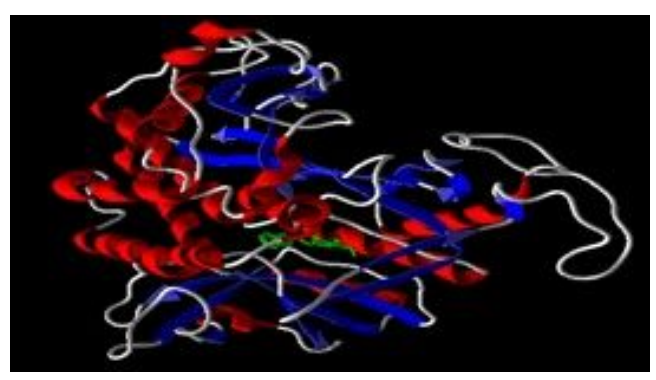

Figure 1

Molecule a Vs (pdb id-3ZXR)

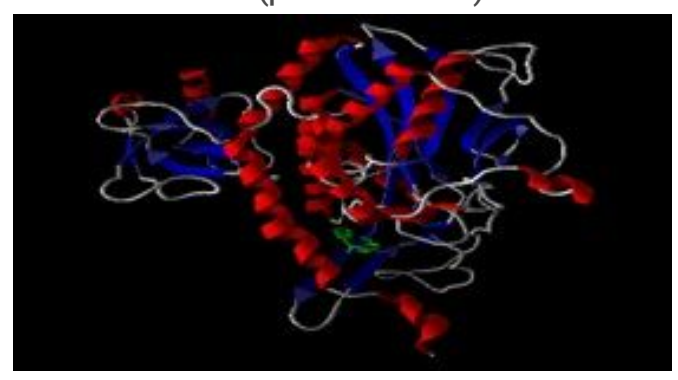

Figure 2

Molecule e Vs pdb id-3ZXR)

\section{Supplementary Files}

This is a list of supplementary files associated with this preprint. Click to download.

- meenaSupportingfiles.docx

- Schemes.pdf 